\title{
The contributions of self-efficacy and perceived organisational support when taking charge at work
}

\author{
Authors: \\ Ike E. Onyishi ${ }^{1}$ \\ Elizabeth Ogbodo \\ Affiliations: \\ ${ }^{1}$ Department of Psychology, \\ University of Nigeria, Nsukka \\ Correspondence to: \\ Ike Onyishi \\ Email: \\ ikeonyishi@yahoo.com \\ Postal address: \\ Department of Psychology, \\ University of Nigeria, Nsukka \\ 08038243959, Enugu State, \\ Nigeria \\ Dates: \\ Received: 06 Apr. 2011 \\ Accepted: 16 Sept. 2011 \\ Published: 25 Jan. 2012 \\ How to cite this article: \\ Onyishi, I.E., \& Ogbodo, E. \\ (2012). The contributions of \\ self-efficacy and perceived \\ organisational support \\ when taking charge at work. \\ SA Journal of Industrial \\ Psychology/SA Tydskrif vir \\ Bedryfsielkunde, 38(1), Art. \\ \#979, 11 pages. http:// \\ dx.doi.org./10.4102/sajip. \\ v38i1.979
}

C 2012. The Authors. Licensee: AOSIS OpenJournals. This work is licensed under the Creative Commons Attribution License.
Orientation: Taking charge as an extra role in the workplace is necessary for the survival of modern firms. Therefore, understanding the personal and organisational factors when one takes charge is critical for organisations.

Research purpose: The aim of the study was to investigate the contributions of self-efficacy and perceived organisational support when taking charge at work.

Motivation for the study: Although many previous studies have examined the antecedents of taking charge in North American business environments, we know little about taking charge in the developing economies of Africa. Research about taking charge will provide valuable information for managers of businesses in developing countries in Africa.

Research design, approach and method: This study used a cross-sectional survey design to examine the contributions of self-efficacy and perceived organisational support to taking charge at work amongst 201 bank workers in Nsukka, Southeast Nigeria.

Main findings: Regression analysis results showed that self-efficacy had a significant relationship with taking charge at work. The results also showed a statistically significant relationship between perceived organisational support and taking charge at work.

Practical/managerial implications: The implications of the results are that interventions that focus on improving self-efficacy will contribute to the behaviours of employees who take charge. In addition, organisations that develop strategies to make employees perceive the organisation as supportive will also have members that engage in more supervisory behaviours.

Contribution/value-add: This study was one of the first attempts to investigate taking charge at work in a developing economy of Africa. The results of the study, that self-efficacy and perceived organisational support have relationships with taking charge at work, will contribute to a better understanding of the concept and to building robust theories.

\section{Introduction}

Organisational viability in complex, technology-driven, quickly changing and turbulent economic times requires employees who are willing to exceed the roles and responsibilities that formal job descriptions define.

In virtually every organisation, there are workers who try to manage established routines to ensure the successful functioning of their organisations and employees who challenge routines by engaging in innovative behaviours in order to achieve the goals of their organisations (Moon, Kamder, Mayer \& Takeuchi, 2008). Morrison and Phelps (1999) argued that the survival of modern firms requires that their workers are highly committed to extra-role behaviours and go beyond their job descriptions to perform tasks that are relevant to achieving their organisations' goals, irrespective of existing rules and procedures.

There has been growing interest amongst researchers about extra-role behaviour in the workplace (Hoffman, Blair, Meriac \& Woehr, 2007; Li, Liang \& Crant, 2010; Lambert, 2000; Suresh \& Venkatammal, 2010). Scholars have argued that this is critical for the effectiveness of organisations because managers cannot foresee all contingencies or fully anticipate the activities that they need employees to perform (Organ, 1988). The interest in extra-role behaviours is partly because they have been generally associated with several positive job outcomes (Podsakoff, Whiting, Podsakoff \& Blume, 2009). Specifically, extra-role behaviours are the behavioural patterns workers exhibit in the workplace that go beyond the specified roles of employees but which are critical for the effectiveness of organisations. However, some have argued that the narrow conceptualisation 
of extra-role behaviour has limited the research (Morrison \& Phelps, 1999).

Most studies on extra-role behaviour have focused mainly on organisational citizenship behaviour (OCB). Organ (1990) described OCB as employee behaviours and gestures that organisations cannot enforce using formal role obligations or elicit in contractual guarantees or through recompense but that benefit them. Specifically, Organ (1988) defined OCB as a special type of work behaviour where individual behaviours that benefit organisations are discretionary, not directly or explicitly recognised in formal reward systems and, taken together, promote the efficient and effective functioning of organisations.

Although these extra-role activities are important, they are not enough to ensure the continued viability of organisations. In addition, organisations need employees who are willing to challenge the current state of operations to bring about constructive change (Morrison \& Phelps, 1999). Because of the initial conceptualisation of $\mathrm{OCB}$, most of the studies on OCB have focused on behaviours that maintain existing rules and procedures. They include helping colleagues, being punctual, not taking excessively long breaks and attending to non-required work functions. More substantial behaviours, which aim at helping organisations to develop, evolve and improve, include taking charge at work (Moon, Van Dyne\& Wrobel, 2005). Therefore, the focus of this study is on taking charge, a neglected form of extra-role behaviour.

Moon, Van Dyne, and Wrobel (2005) described it as an often-overlooked aspect of innovative behaviour that is also volitional in nature. Taking charge entails voluntary and constructive efforts, by individual employees, to effect organisationally functional change with respect to how employees work within the context of their jobs, work units or organisations (Morrison \& Phelps, 1999). Therefore, taking charge is extra-role behaviour (Moon, et al., 2008; Morrison \& Phelps, 1999; Onyishi, 2007). This implies that that it not mandatory and organisations do not formally require it.

When they take charge at work, employees tend to initiate or create new procedures that they consider appropriate, irrespective of existing rules. It is similar to other forms of extra-role behaviours because it is a discretionary attempt (not formally required) to initiate and effect positive change (inherently change-orientated). It aims to improve and benefit organisations instead of being rooted in personal gain (Moon, et al., 2008).

However, one can distinguish taking charge from other extrarole efforts. Unlike OCB and other related behaviours that are affiliative, it is a challenging and functional organisational behaviour (McAlister, Kamdar, Morrison \& Turban, 2007). Van Dyne, Cummings, and Parks (1995) refer to taking charge as being 'challenging-promotive' because it fits into the general class of extra-role behaviours. They separated it using two dimensions: promotive (encouraging something to start) or prohibitive (encouraging something to stop). These are behaviours that are either affiliative (concerned with relationships and cooperation) or challenging (changeorientated and concerned with ideas and issues). Moon et al. (2008) see taking charge as innovative citizenship behaviour and acknowledge that the behaviour is change-orientated.

Evidence from several sources highlights the potential value of taking charge. Van Maanen and Schein (1979) argued that, because organisations require innovation and change to remain viable, it is often valuable for employees to reject and redefine aspects of their work roles. Similarly, Staw and Boettger (1990) emphasised how important it is for employees to act to correct faulty procedures or misdirected work goals. They argued that employees who go beyond the call of duty to accomplish incorrectly specified roles or who are extra conscientious in following counterproductive procedures might cause organisations to become dysfunctional.

If current role definitions, procedures or policies are inappropriate or inefficient, it may be more appropriate for employees to channel some of their extra-role efforts into changing rather than maintaining the status quo. Researchers have noted the importance of employee-initiated change for long-term organisational adaptability and have become increasingly concerned with how organisations can promote employee initiative (Frohman, 1997; Burgelman, 1994; Bunce \& West, 1995). Parker and Collins (2010) listed taking charge and other change-initiating behaviours in organisations, like 'expressing voice' (LePine \& Van Dyne, 1998) and proactive service performance (Rank, Carsten, Unger \& Spector, 2007), as being critical for the effectiveness of organisations.

Several researchers have studied taking charge in cultures that include those of North America (Morrison \& Phelps, 1999; Van Dyne, Cummings, \& Parks, 1995) and of Asia (McAllister, Kamdar, Morrison \& Turban, 2007). However, researchers have not explored whether the findings of these studies, to explain work behaviour, apply to the developing economies of Africa, especially Nigeria. Work attitudes in the cultures of North America and Asia may differ from those in the Nigerian business environment (Hofstede, 1984). Research has shown that extra-role behaviour has different meanings in different cultures (Farh, Earley \& Lin, 1997; Farh, Zhong \& Organ, 2004).

In order to understand fully the construct of extra-role behaviour, it is important to generate data across cultures and environments, including from business environments that differ from those of North America, where researchers have conducted most of the studies. In most Nigerian work environments, for example, the general attitude to work seems to be poor. Employees seem to care less about their organisations and more about their personal gain (Munene, 1995). Munene (1995, p. 111) described a situation he referred to as a 'not on seat' phenomenon. Here employees report to work on time only to leave their workplaces soon 
after and return hours later. They leave to attend to their personal problems and other non-work related issues to the detriment of their work roles. This attitude seems to be widespread in most organisations in Nigeria. In these organisations, people work only within the scope of their job descriptions. They seem to follow the rules rather than try to initiate actions that will benefit their organisations. Munene (1995) noted that extra-role behaviours in organisations are relatively few in many African countries and went further to propose that organisations should try to encourage these behaviours in order to improve the economies of African nations. Encouraging employees to take charge at work may become important for the survival of firms in the developing economies of Africa and help them to rise to the challenges of global competition.

Based on the envisaged advantages of taking charge at work in the developing economies of Africa, it is therefore necessary to investigate the possible factors that could encourage, or discourage, taking charge.

\section{Research objectives}

The purpose of this study was to investigate the contributions of self-efficacy and perceived organisational support to taking charge at work amongst employees in the banking sector in Nigeria.

The Nigerian business environment seems to have employees who are less willing to go the extra mile (Ewurum, 2006) to initiate workplace change that will enable their organisations to cope with the challenges of global competition. It has become obvious that today's employees need to engage in extra-role behaviour to ensure increased productivity. Therefore, the researchers propose that it is necessary to investigate factors that promote these extra-role and changeorientated behaviours, like taking charge, in Nigerian workers.

Consequently, the study has two specific objectives:

- Objective 1: To investigate the contributions of self-efficacy to taking charge at work.

- Objective 2: To investigate the contributions of perceived organisational support to taking charge at work.

Theresearchers envisage that this study will help organisations to understand the individual and organisational variables that encourage taking charge at work. They hope that knowledge from the study will provide a basis for effective managerial intervention to develop employees who are willing to engage in extra effort to initiate workplace changes that will make organisations become more efficient and effective.

\section{Theoretical background and research hypotheses}

Research has shown that individual and contextual (organisational) variables moderate the extent to which employees take charge in organisations (Morrison \& Phelps, 1999).
Organisational performance depends on people. Therefore, industrial or organisational psychologists have explored a great deal of relevant knowledge about the possible factors that are necessary to facilitate effectiveness in organisations (Ivancevich, Konopaske \& Matteson, 2005). However, researchers have hardly investigated organisational behaviour in the Nigerian business environment. Nevertheless, the findings from these neglected areas could help to refine concepts about organisational behaviour, including extra-role behaviour like taking charge at work.

In Nigeria, the general perception is that average Nigerian workers seem unwilling to go the extra mile and only perform the tasks that enable them to earn their salaries (Ewurum, 2006). However, many believe that most organisations in Nigeria do not care about the welfare of their employees and that the top managers of some organisations seem to care more about their own gains rather that those of the rest of the employees. However, it is possible that some employees, even in the face of these negative perceptions of their organisations, still strive to go the extra mile by initiating change that will benefit their organisations. In addition, individual variables, like efficacy beliefs, may inspire this positive organisational behaviour. Therefore, the present study focuses on self-efficacy and perceived organisational support as important determinants of taking charge at work amongst employees in the banking sector in Nigeria.

Self-efficacy is the belief people have in their ability to perform in a certain way or engage in a specific behaviour to achieve their desired goals. It is the belief that people are able to perform the actions required to manage difficult or novel tasks and to cope with the adversity associated with demanding situations (Bandura, 1997; Ivancevich, et al., 2005; Kreitner \& Kinicki, 2004; Kreitner, Kinicki, \& Buelens, 2002). Unlike efficacy, which is the power to produce an effect, selfefficacy is the belief that people have the power to produce that effect. This belief could be accurate or inaccurate. Selfefficacy makes a difference in how people feel, think and act (Bandura, 1997). Its characteristics are that it is competencebased, prospective, action-related and commonly associated with task-specific or domain-specific roles. It arises from the gradual acquisition of complete, cognitive, social, linguistic, and/or physical skills through experience. Although selfefficacy is a task- or situation- specific construct, Sherer, Maddux, Mercandante, Prentice-Dunn, Jacobs, and Rogers (1982) argued that people also have generalised self-efficacy beliefs that apply across situations. However, Mitchell and Daniels (2003) saw it as a relatively malleable, task-specific belief.

Expectancy theory (Vroom, 1964) holds that people are motivated to behave in ways that produce desired outcomes. That is, people choose to behave from amongst alternative courses of action based on their expectations of what there is to gain from each action (Kreitner \& Kinicki, 2004; Ivancevich, et al., 2005). According to expectancy theory, the tendency to act in a certain way depends on the strength of expectancy 
that a given consequence (or outcome) will follow the act and on the attractiveness of that consequence (or outcome) to the actors (Kreitner \& Kinicki, 2004). The expectations of people that certain levels of effort will produce their intended goals affect their motivation. The employees' perceived chances of achieving various outcomes because they have accomplished their goals also influence their motivation.

Therefore, the expectancy model may help us to understand the decision-making process behind taking charge at work (Morrison \& Phelps, 1999). Vroom (1964) had earlier suggested that employees would weigh anticipated costs against anticipated benefits when they decide whether to engage in certain behaviours. With regard to taking charge, employees will assess the probability that taking charge will be successful. This shows that an assessment of anticipated consequences will play an important role in the decision to take charge (Morrison \& Phelps, 1999). Therefore, taking charge involves a calculated decision-making process in which people assess the likelihood that they will succeed and the likely consequences of their actions, like whether the risks of taking charge outweigh its benefits. It follows that people are likely to take charge when they feel that they will succeed with change-orientated behaviour. This is consistent with self-efficacy beliefs.

Studies have shown that generalised self-efficacy could predict some positive job outcomes that are quite critical to taking charge at work. They include personal initiative at work (Speier \& Frese, 1997); goal setting (Locke \& Latham, 1990); proactive job performance (Griffin, Neal, \& Parker, 2007; Ohly \& Fritz, 2007; Parker \& Collins, 2010; Parker, Williams \& Tumer, 2006) and overall job performance (Stajkovic \& Luthans, 1998).

Employees with high self-efficacy tend to anticipate a higher likelihood of success and are more likely to attempt this behaviour. Withey and Cooper (1989) argue that individual differences in beliefs about personal efficacy will affect the decision about whether to engage 'in voice'. This is any attempt to change, rather than to escape from, an objectionable state of affairs. It suggests that self-efficacy could imply taking charge at work.

Evidence shows that self-efficacy will affect the perceived costs and benefits associated with taking charge. Employees with high self-efficacy tend to underestimate the risks associated with any given course of action and tend to overestimate their ability to overcome those risks (Sitkin \& Pablo, 1992). In a direct study of relationships between self-efficacy and taking charge amongst 275 white-collar employees in the United States of America, Morrison and Phelps (1999) found that self-efficacy has a positive relationship with taking charge. In another study, McAllister, et al. (2007) also found that perceived efficacy has a positive relationship with taking charge amongst 225 engineers in an oil refinery in India.

There is growing concern about the universality of the selfefficacy construct. Researchers (like Luszczynska, Gutièrrez-
Dona, \& Schwarzer, 2005) see self-efficacy as a universal construct and maintain that it characterises a basic belief that is inherent in all people irrespective of their culture. Although Luszczynska, et al. (2005) attempted to investigate this assumption, they conducted their study in cultures that may be different from those in the developing countries of Africa.

The present study aims to verify and test the applicability of earlier findings about the relationships between selfefficacy and taking charge at work in the Nigerian business environment. Replication may allow generalising the previous findings to the developing countries of Africa. Therefore, the researchers hypothesised that self-efficacy has a relationship with taking charge amongst employees in Nigeria.

Organisations that provide enabling or conducive environments for their employees tend to empower employees by encouraging and/or assisting employees and groups to make decisions that affect their work environments. Conger and Kanungo (1988) posit that empowerment is a process of increasing feelings of self-efficacy amongst employees. Empowerment also helps to develop the abilities of employees (Kreitner, et al., 2002). Organisations empower employees by giving support or adopting a leadership style that suits or boosts employee performance.

Scott and Bruce (1994) emphasised that employees are more likely to be innovative if they perceive that there is a 'climate for innovation' or that their organisations support new ideas and change efforts. Research also suggests that top management openness is an important variable that affects taking charge (Morrison \& Phelps, 1999). Therefore, this study aims to examine the contribution of organisational antecedents via perceived organisational support to taking charge at work in the Nigerian business environment.

Eisenberger, Huntington, Hutchison, and Sowa (1986) developed the concept of perceived organisational support to explain the development of employee perceptions of, and commitment to, organisations. They proposed that employees develop global beliefs about the extent to which organisations value their contributions and care about their well-being. They referred to those global beliefs as perceived organisational support.

Adopting a social exchange framework, Blau (1964) and Eisenberger et al. (1986) argued that these beliefs underpin employees' inferences about their organisations' commitment to them. This, in turn, contributes to the employees' commitment to their organisations. High levels of perceived organisational support create feelings of obligation, whereby employees feel that they ought to be committed to their employers and feel an obligation to return the employers' commitment by engaging in behaviours that support their organisations' goals. In other words, employees seek a balance in their exchange relationships with their organisations by having attitudes and behaviours commensurate with the degree of employers' commitment to them as people. 
Employees who are emotionally committed to their organisations perform better, are absent less often and are less likely to leave their jobs (Mathieu \& Zajac, 1990; Meyer \& Allen, 1997; Mowday, Porter, \& Steers, 1982). Perceptions that their organisations value and care for them also increase employees' trust that their organisations will fulfil their exchange obligations of recognising and rewarding desired employee attitudes and behaviours. Employees tend to take a long-term approach to social exchange relationships at work and the pattern of reciprocity determines the perceived balance of exchanges over time (Blau, 1964; Rousseau, 1989).

Scholars, who argue from the social exchange perspective, see employment as the exchange of effort and loyalty for tangible benefits and social rewards (Bateman \& Organ, 1983; Brief \& Motowidlo, 1986; Mowday, et al., 1982; Organ \& Konovsky, 1989; Steers, 1977). When one person treats another well, the reciprocity norm obliges the return of favourable treatment (Gouldner, 1960). To the extent that both employees and employers apply the reciprocity norm to their relationships, both parties reciprocate the favourable treatment that either party receives. This leads to beneficial outcomes for both. Employees also value perceived organisational support as assurance that their organisations will help them when they need assistance to perform their jobs effectively and to deal with stressful situations (George, Reed, Ballard, Colin, \& Fielding, 1993). Therefore, the researchers argue that perceived high organisational support has a relationship with several positive job outcomes, including taking charge at work.

Theorists use social exchanges and the norm of reciprocity to explain the workplace contributions of perceived organisational support to taking charge at work. Their value lies in the positive, beneficial actions that organisations and/ or their representatives direct at their employees. They help to establish high quality exchange relationships that create obligations for employees to reciprocate in positive beneficial ways (Settoon, Bennett \& Liden, 1996). They also increase the likelihood that the partners to the exchange will notice these efforts (Blau, 1964; Gouldner, 1960). Therefore, extrarole behaviours, like taking charge, occur when employees respond to the obligations they feel to their organisations (Moorman, 1991; Organ, 1990).

Previous studies have shown that perceived organisational support (POS) relates to several positive work behaviours, including extra-role behaviours. Eisenberger, Armeli, Rexinkel, Lynchand Rhoades (2001) investigated the role of reciprocation in the relationship of perceived organisational support to employees' affective organisational commitment and job performance. The results of their study showed that POS was associated with felt obligation and positive mood at work. Perceived organisational support and felt obligation both had a relationship with affective commitment and the three performance dimensions (in-role performance, organisational spontaneity and withdrawal behaviour).
Settoon, et al. (1996) studied the relationship between perceived organisational support, leader-member exchange (LMX) and employee reciprocity (attitudes and behaviour). Their study showed that perceived organisational support and leader-member exchange had stronger correlations with commitment to organisations and citizenship behaviours.

Moon et al. (2008) also found that procedural justice at the organisational level had a positive relationship with taking charge when a co-worker evaluated them, whilst procedural and distributive justice had positive relationships with taking charge when a supervisor assessed them. However, studies have not focused directly on investigating the relationship between perceived organisational support and taking charge at work, especially in a corporate environment like the Nigerian business setting where there seems to be general low motivation and negative attitudes to work, which discourage extra-role behaviours (Ewurum, 2006).

Researchers have linked supportive behaviours from supervisors and organisations to extra-role behaviour like OCB (Organ \& Ryan, 1995; Settoon, et al., 1996). However, it is not clear whether one can use these findings to explain extra-role behaviours that supervisors and organisations direct towards initiating workplace change, like taking charge. Therefore, the researchers hypothesise that perceived organisational support will have a relationship with taking charge at work.

In the subsequent sections of this paper, the researchers outline the research design, including the research approach and methods they used to carry out the study. Later they present the results of the study. They include intercorrelations and the results of the regression analyses. Finally, they discuss the results, highlight the implications of the findings for research and practice and outline some limitations of the study.

\section{Research design Research approach}

The study adopted a quantitative research method to investigate the contributions of self-efficacy and perceived organisational support to taking charge at work amongst workers in banks in Nsukka, a small city in southeast Nigeria. The study used a cross-sectional design. According to Shaughnessy, Zechmeister and Zechmeister (2000), a crosssectional design is one of the most commonly used survey designs. It involves selecting one or more samples from the population at one time. The researchers use the information they collect from the sample or samples to describe the population at that point in time.

The researchers measured all the variables using a self-report questionnaire. They subjected the responses they obtained to statistical analysis. They used regression analyses to test the contributions of the predictor variables (self-efficacy and perceived organisational support) to taking charge at work. 


\section{Research method}

\section{Research participants}

The participants consisted of 201 employees from 13 banks. Ten were commercial banks and three were micro finance banks located in a small metropolitan area in southeast Nigeria. There were 337 employees in the 13 banks operating in the city at the time of the research.

The researchers selected only the participants who volunteered to participate in the study. Of the 201 participants who responded to the survey, $133(66.2 \%)$ were men. Of the respondents, $143(71.14 \%)$ indicated that they had permanent appointments, whilst $58(28.86 \%)$ had contracts. The ages of the respondents ranged between 18 and 50 years. They had an average age of 27.4. The average tenure in the organisation was 10.29 years. The minimum education qualification of the participants was a senior school certificate.

\section{Measuring instruments}

The researchers used the questionnaire to elicit information from the respondents. They divided the questionnaire into two parts. The first part required information about demographic data like age, gender, contract status, education qualifications, occupational level as well as tenure in the organisation and department. The second part focused on measures of variables of interest. The researchers used three instruments for the second part. They were the Taking Charge at Work Scale, the Self-efficacy Scale and the Survey of Perceived Organisational Support.

The Taking Charge at Work Scale of Morrison and Phelps (1999): The researchers used this measure to elicit information about taking charge from the employees they surveyed. The researchers used the instrument, which Onyishi (2007) adapted earlier as a self-report measure in Nigeria, in the study. Morrison and Phelps (1999) originally developed the Taking Charge at Work Scale as a 10-item co-worker rating scale that ranges from 'strongly agree' to 'strongly disagree'. Morrison and Phelps reported a Cronbach's alpha reliability of .95. The result of the confirmatory factor analysis (CFA) of Morrison and Phelps showed that the taking charge measure is distinct from both in-role behaviour and other forms of extra-role behaviours.

In the present study, the researchers converted the scale to a self-report measure to enable participants respond to other independent variable measures in similar ways. They also adopted the five-point scale to range from 'strongly agree' (5) to 'strongly disagree' (1) for the self-report measure.

Using self-report measures of extra-role and pro-social organisational behaviours has gained prominence in organisational behaviour literature (Chattopadhyay, 1999; Grant, 2008) and has been found to be as valid and reliable a measure as other methods of rating are. A sample item is 'I try to adopt improved procedures in doing my work.' The Cronbach's alpha of .92 shows that the items in the questionnaire have internal consistency.
The Self-Efficacy Scale (SES): This 30-item inventory measures the social component of self-efficacy from both interpersonal and intrapersonal perspectives. Sherer et al. (1982) constructed and validated it. It was adapted for the use of professionals in Nigeria after several years of research at re-standardising it in order to improve its suitability to, and relevance for, Nigerians. It is a five-point Likert type structure where 1 represents 'disagree strongly' whilst 5 represents 'agree strongly'. Its purpose is to measure self-perceived competence and effectiveness in work performance as well as efficacy in handling social relationships.

Sherer et al. (1982) provided the original psychometric properties for American samples whilst Ayodele (1998) provided the properties for Nigerian samples. Sherer et al. (1982) reported a Cronbach's alpha of .86. Ayodele (1998) obtained a concurrent validity coefficient of 23 by correlating the SES with the Mathematics Anxiety Rating Scale. A sample item is 'When I am confronted with a problem, I can usually find several solutions'. The internal consistency coefficient for the present study is .81 .

The Survey of Perceived Organisational Support (SPOS): The researchers used a short version of the SPOS, which Eisenberger, Huntington, Hutchison and Sowa (1986) developed, in this study. The original version of SPOS is a 30-item questionnaire that measures employees' perceived support from their organisations. The questionnaire is a seven-point Likert type structure where 1 represents 'strongly disagree' and 7 represents 'strongly agree'. Some of the statements had positive wordings whilst others were negative in their wording. An example of a positively worded item is 'The organisation takes pride in my accomplishment at work', and a sample of a negatively worded item is 'Even if I did the best job possible, the organisation would fail to notice'.

Reliability and item analysis on the initial data that Eisenberger et al. (1986) collected yielded a reliability coefficient (Cronbach's alpha) of .97. Item-total correlations ranged from .47 to .83 . The researchers used the 16 items that loaded highly in the factor analysis of Eisenberger et al. (1986). They adopted the shortened version of the scale for the present study. Researchers who used this shortened version of SPOS have also reported high reliability scores (Onyishi, 2006; Randall, Copanzano, Bormann \& Borman \& Birjulin, 1999; Wayne, Shore \& Liden, 1997). To make responses easier, Onyishi (2006) adapted a five-point Likert response format instead of the seven-point format the initial study used. The researchers adopted this format for the current study. The internal consistency coefficient (Cronbach's alpha) for the present study is .86 .

\section{Research procedure}

The researchers administered the instruments directly to all the available participants at the time of the study. The items in the instruments were in English because it is the official language for conducting business in Nigeria. All the 
participants understand the language. Following the ethical guidelines for conducting psychological research in Nigeria, they assured the participants that their participation in the study was voluntary. In addition, they obtained the informed consent of the participants before the study began. The data collection processes also ensured the confidentiality of the responses. The researchers gave all the employees in the 13 banks copies of the questionnaire at the point of distribution except those who were not present, on leave, sick or who had declined to participate in the survey. They asked the respondents to complete the surveys and return them immediately if it was convenient or to retain the surveys, complete them and return them directly to the researchers or to an appointed member of the administrative staff in sealed envelopes that they provided.

Of the 320 copies of the questionnaire the researchers distributed, respondents returned 225. This is an overall response rate of $70.3 \%$. Because respondents completed some of the questionnaires incorrectly, the researchers discarded 24 of the returned questionnaires. As a result, 201 (62.8\% of the total survey) employee surveys comprised the final sample. The researchers used these responses for statistical analysis.

\section{Statistical analysis}

The researchers used the Statistical Package for Social Science (SPSS) version 16 (Dancey \& Reidy, 2002) to analyse the data. They used hierarchical regression to assess the amount of incremental variance each type of predictor variable explained.

Firstly, the researchers entered the control variables (gender, age, tenure in the organisation, employment status and education). The researchers then entered the predictor (selfefficacy), followed by perceived organisational support, before capturing the product terms for the interaction between self-efficacy and perceived organisational support. The researchers assessed the significance of each step using $R^{2}$. $R^{2}$ enabled the researchers to determine the contributions of the predictor variables to variations in taking charge at work. They investigated the multi-collinearity assumptions on the predictor variables before conducting these analyses.
They found that the variables had a linear relationship and converted the data to Z-scores before establishing an interaction term, as Aiken and West (1991) suggested. In addition, a test of tolerance showed that multi-collinearity was not a problem in the regression equation $(\mathrm{VIF}=1.03)$.

\section{Results}

Table 1 gives the descriptive statistics and correlation coefficients for the study variables. Table 2 gives the regression results.

The mean scores for taking charge was $40.66(\mathrm{SD}=4.52)$. This shows that most of the participants reported high taking charge behaviour. Of the control variables, only employment status had a significant relationship with taking charge at work $(r=.17, p<.05)$. Self-efficacy had a significant relationship with taking charge $(r=.32, p<.01)$. Perceived organisational support also had a significant relationship with taking charge at work $(r=.29, p<.01)$.

Table 2 shows that the control variables, as a block, explained an insignificant percentage of the variance in taking charge. The regression analyses showed that self-efficacy contributed $8 \%$ to the unique variance in taking charge at work $(\beta=.29$, $\left.\Delta R^{2}=.08, p<.001\right)$.

This was significant and confirms the hypothesis that selfefficacy has a significant relationship with taking charge at work. It also confirmed the hypothesis that perceived organisational support has a significant relationship with taking charge at work. The results showed that perceived organisational support contributed an additional 3\% to the unique variance in taking charge at work $\beta=.18$, $\Delta R^{2}=.03, p<.01$ ) over and above the control variables and selfefficacy. The interactive effect of self-efficacy and perceived organisational support on taking charge was not statistically significant.

\section{Discussion}

The purpose of this study was to explore the contributions of self-efficacy and perceived organisational support to taking

TABLE 1: Means, standard deviations and inter-correlations between study variables.

\begin{tabular}{|c|c|c|c|c|c|c|c|c|c|c|c|c|}
\hline \multirow[t]{2}{*}{ Variable } & \multirow[t]{2}{*}{ Variable } & \multirow[t]{2}{*}{ Cronbach's alpha } & \multirow[t]{2}{*}{$M$} & \multirow[t]{2}{*}{ SD } & \multicolumn{8}{|c|}{ Variable } \\
\hline & & & & & 1 & 2 & 3 & 4 & 5 & 6 & 7 & 8 \\
\hline 1 & Gender & - & .69 & .48 & 1 & - & - & - & - & - & - & - \\
\hline 2 & Age & - & 28.43 & 5.61 & $.16^{*}$ & 1 & - & - & - & - & - & - \\
\hline 3 & Tenure in the organisation & - & 19.79 & 25.82 & .04 & $.38^{* *}$ & 1 & - & - & - & - & - \\
\hline 4 & Employment status & - & .73 & .44 & $.17^{*}$ & $.25^{* *}$ & $.16^{*}$ & 1 & - & - & - & - \\
\hline 5 & Education & - & 2.14 & .54 & $-.22 * *$ & $-.18 * *$ & $-.18 * *$ & $.39 * *$ & 1 & - & - & - \\
\hline 6 & Self-efficacy & .81 & 86.95 & 10.87 & .09 & .04 & -.05 & .11 & -.10 & 1 & - & - \\
\hline 7 & $\begin{array}{l}\text { Perceived organisational } \\
\text { support }\end{array}$ & .86 & 60.10 & 8.86 & .11 & -.02 & -.14 & .00 & .03 & $.32 * *$ & 1 & - \\
\hline 8 & Taking charge & .92 & 40.66 & 4.52 & .05 & .08 & .05 & $.17 *$ & -.05 & $.30 * *$ & $.29 * *$ & 1 \\
\hline
\end{tabular}

Note: A total of 201 employees completed the questionnaires. The researchers used the coding that follows to explain the pattern of coding they used during the SPSS analysis:

- with regard to gender, 0 denotes man, 1 denotes woman

- with regard to employment status, 0 denotes contract, 1 denotes permanent

- with regard to education, 1 denotes a higher degree, 2 denotes a first degree, 3 denotes a diploma and 4 denotes a high school certificate.

The researchers entered the raw scores of other variables as they collected them. They coded self-efficacy and perceived organisational support so that higher scores show greater self-efficacy or perceived organisational support.

$*, p<.05$

$*, p<.05$
$* *, p<.01$ 


\begin{tabular}{|c|c|c|c|c|}
\hline \multirow[t]{2}{*}{ Variables } & \multicolumn{4}{|c|}{ Steps } \\
\hline & 1 & 2 & 3 & 4 \\
\hline Age & .03 & .02 & .02 & .03 \\
\hline Gender & .02 & .01 & -.01 & .01 \\
\hline Level of education & .02 & .04 & .02 & .02 \\
\hline Tenure in the organisation & .01 & .04 & .06 & .06 \\
\hline Employment status & $.16^{*}$ & .14 & .14 & .13 \\
\hline Self-efficacy & - & $.29 * * *$ & $.23 * * *$ & .07 \\
\hline Perceived organisational support & - & - & $.18^{* *}$ & -.01 \\
\hline Self-efficacy $\times$ perceived organisational support & - & - & - & .30 \\
\hline$R^{2}$ & .03 & .11 & .14 & .14 \\
\hline$R^{2}$ change & .03 & $.08 * * *$ & $.03^{* *}$ & .001 \\
\hline$F$ change & $F(5,195)=1.23$ & $F(1,194)=17.79$ & $F(1,193)=6.64$ & $F(1,192)=0.14$ \\
\hline$F$ values & $F(5,195)=1.24$ & $F(6,194)=4.09 * * *$ & $F(7,193)=4.55^{* * *}$ & $F(8,192)=3.98$ \\
\hline
\end{tabular}

charge at work amongst bank employees in Nigeria. The study built on previous research that focused on self-efficacy as an antecedent of taking charge at work in western business contexts. The researchers expected that self-efficacy would also have a relationship with taking charge amongst Nigerian bank workers. Based on the social exchange perspective and on previous empirical findings, they also hypothesised that perceived organisational support will have a relationship with taking charge at work amongst bankers in Nigeria.

The study showed that self-efficacy had a significant relationship with taking charge. This result showed that the participants were more likely to take charge to the extent that they had a high level of self-efficacy for bringing about change in their work places.

The results are consistent with the findings of Morrison and Phelps (1999) that taking charge has a relationship with selfefficacy. These results showed that context and individual characteristics affect decisions about whether or not to take charge (Morrison \& Phelps, 1999). Therefore, even in the same organisations, some employees may be more likely to take charge than others may - especially those with high selfefficacy.

The results of this study are also consistent with those that Parker et al. (2006), Parker and Collins (2010), Locke and Latham (1990), and Shea and Howell (2000) obtained. Their results showed that job performance had a significant and positive correlation with self-efficacy. Greater self-efficacy had a relationship with greater performance.

Expectancy theory supports the belief that self-efficacy has a relationship with taking charge at work, especially when employees perceive a favourable combination of what is important to them and what they expect as a reward for their efforts. When employees feel confident about their ability to attain high levels of performance, which are associated with outcomes (rewards), they are likely to engage in behaviours that are commensurate with their outcomes. That selfefficacy predicts taking charge at work has several practical implications. According to Bandura (1986), self-efficacy is an activity that develops through four processes:

- past experience or enactive mastery or repeated performance accomplishments

- vicarious experience or modelling

- verbal or social persuasion

- automatic or physiological arousal.

Employees may experience enactive mastery and 'learn by doing' by starting with small, low-risk ventures. The positive feedback of task achievement increases self-efficacy levels. Positive feedback creates an upward efficacy-performance relationship (Lindsley, Brass, \& Thomas, 1995). After gaining confidence, employees could gradually move into larger, riskier endeavours. Therefore, it is not surprising that employees who engage in behaviours like taking charge have high self-efficacy. The results of this study also showed that employees are more likely to take charge when they see their organisations as supportive. The result is consistent with that of Morrison and Phelps (1999). They discovered that top management openness, which is organisational supportive behaviour, has a significant relationship with taking charge.

The current study highlights the relevance of contextual variables in pro-social or extra-role behaviour. When employees feel that resistance will follow engagement in change-orientated activity or will entail high political risk, the tendency to engage in taking charge will decrease. On the other hand, when employees perceive that their organisations respond favourably to a risky change-orientated activity or support constructive efforts and contributions to bring about improvement, they will feel more confident that taking charge will be effective and will be less concerned about its potential costs.

Social exchange theories support this finding. Researchers into organisations have used these theories to describe the motivational basis behind employee behaviour and the formation of positive employee attitudes (Settoon et al., 1996). This is because positive, beneficial actions, which organisations and/or their representatives direct at 
employees and when those actions go beyond the demands of social roles (Wayne, et al., 1997), help to establish high quality exchange relationships. These relationships create obligations for employees to reciprocate in positive and beneficial ways.

These results have several implications for the Nigeria business environment and other business cultures where organisations are selfish and care little about their employees and other stakeholders. Supportive behaviours from organisations in this context are likely to send signals to employees that their organisations value them. This may result in workers engaging in positive change-orientated behaviours, like taking charge.

This study makes some important contributions to, and sheds some light on, the effective management of employees in general and the knowledge of workers. This is particularly relevant to the importance of how employees see themselves and their perceptions of the support that is available from organisations. Perceived organisational support has a relationship with taking charge. Therefore, organisations should find ways of promoting better perceptions of organisational support in their employees. In work environments, like that of Nigeria where organisations are oppressive and where top managers defraud their organisations to the detriment of the employees and other stakeholders, the need for supportive behaviour is critical.

Supportive behaviour from organisations could help to motivate employees to make extra efforts to help their organisations become viable. It will also help to produce employees who are ready to take initiatives that will bring positive change to their organisations. Organisations should introduce supportive practices that help to induce higher levels of perceived organisational support.

The practices that organisations can use to foster higher levels of perceived organisational support include offering satisfactory rewards, providing career opportunities, supporting work-family balance, building high quality work relationships and improving communication between top managers and other employees. These practices will help employees to meet their needs at different levels. They can lead to positive employee attitudes and behaviours, which incorporate taking charge. These attitudes and behaviours are indispensable for the survival of organisations in everintensifying global competition.

\section{Limitations of the study}

The limitations of this study make it difficult to generalise the results of this study. One limitation is that the researchers surveyed only employees in the banking sector. Therefore, generalising these results to other categories of workers may not be appropriate. The size of the sample is relatively small compared to the population of bankers in Nigeria. Therefore, this also limits generalising the results of the study to the whole banking industry in Nigeria.
Another limitation is that this study was cross-sectional in nature. A cross-sectional design yields correlational rather than causal evidence. A further limitation is that the researchers measured the data for all variables using selfreporting scales. Collecting data from several sources reduces the common-method bias associated with a single source. Therefore, it would have been preferable to collect objective data from supervisors' ratings when employees take charge.

It was impossible to verify the accuracy and honesty of the employees' self-reported data. However, the anonymity of the responses and the confidentiality assurance the researchers gave to the participants may have reduced any bias that could have occurred because of the method they adopted in the study.

An additional limitation is that, although this study provides a useful step toward understanding the construct of taking charge, it was able to assess only a few of the many variables that may encourage this activity.

\section{Suggestions for further research}

Future research should focus on identifying a broader set of predictors of taking charge. This study points to some future research that could help us to understand the phenomenon of interest further and to overcome the limitations of the current research.

Firstly, the findings of this study give some insight into how self-efficacy and perceived organisational support could influence the employee attitudes and behaviours that contribute to taking charge. However, to understand the relationships between these variables and taking charge more fully, it would be helpful for future research to collect data from employees in different organisations. Researchers could include variables of individual differences in future research in order to explain why implementing the same practices could generate different perceptions amongst employees. For example, employees with positive affectivity tend to perceive more support from their organisations (Yoon \& Thye, 2000). Accordingly, individual differences in affectivity could lead employees to have different perceptions of the practices their organisations use. This, in turn, could result in different levels of perceived organisational support and different attitudinal and behavioural outcomes.

Another direction for future research is to study the antecedents and outcomes of taking charge through a longitudinal study. Longitudinal research would increase our understanding of taking charge by investigating how organisations develop it in their employees over time and whether the effects of these antecedent variables would weaken or strengthen over time.

Despite these limitations, this study contributes to the literature by investigating the contributions of self-efficacy and perceived organisational support to taking charge at work in the Nigerian business environment. Taking charge 
at work is a critical job outcome for organisations, especially where the general attitude to work is poor. Therefore, building a supportive organisation with a highly efficacious workforce holds the key to empowering employees to take charge at work and initiate the needed workplace positive changes that will enable organisations to remain viable in a highly competitive global arena.

\section{Acknowledgements Competing interests}

The authors declare that they have no financial or personal relationship(s) which may have inappropriately influenced them in writing this paper.

\section{Authors' contributions}

I.O. (University of Nigeria) was the project leader, was responsible for the research design, performed the statistical analysis and was involved in preparing the manuscript. E.O. (University of Nigeria) conducted the data collection and was involved in preparing the manuscript.

\section{References}

Aiken, L.S., \& West, S.G. (1991). Multiple regression: Testing and interpreting interactions. Newbury Park, CA: Sage.

Ayodele, E.E. (1998). Evaluation of correlates of mathematics anxiety. Unpublished M.Sc. Research Project, Department of Psychology, University of Lagos.

Bandura, A. (1986). Social foundation of thought and action: A social-cognitive theory. Englewood Cliffs, N.J.: Prentice Hall.

Bandura, A. (1997). Self-efficacy: The exercise of control. New York: Freeman.

Bateman, T.S., \& Organ, D.W. (1983). Job satisfaction and the good soldier: The relationship between affect and employee 'citizenship.' Academy of Management Journal, 26, 587-595. http://dx.doi.org/10.2307/255908

Blau, P. (1964). Exchange and power in social life. New York: Wiley.

Brief, A., \& Motowidlo, S. (1986). Prosocial organizational behaviors. Academy of ManagementReview,11,710-725.http://dx.doi.org/10.5465/AMR.1986.4283909, http://dx.doi.org/10.2307/258391

Bunce, D., \& West, M. (1995). Self Perceptions and perceptions of group climate as predicators of individual innovation at work. Applied Psychology: An Internationa Review, 44, 199-215. http://dx.doi.org/10.1111/j.1464-0597.1995.tb01076.x

Burgelman, R. (1994). Fading memories: A process theory of strategic business exit in dynamic business environments. Administrative Science Quarterly, 39, 24-56. $\mathrm{http}: / / \mathrm{dx}$.doi.org/10.2307/2393493

Chattopadhyay, R. (1999). Beyond direct and symmetrical effects: The influence of demographic dissimilarity on organizational citizenship behavior. Academy of Management Journal, 42(3), 273-287. http://dx.doi.org/10.2307/256919

Conger, J.A., \& Kanungo, R.N. (1988). The empowerment process: Integrating theory and practice. Academic of Management Review, 13, 471-482. http://dx.doi org/10.5465/AMR.1988.4306983, http://dx.doi.org/10.2307/258093

Dancey, C.P., \& Reidy, J. (2002). Statistics without maths for psychology: Using SPSS for Windows. (2nd edn.). London: Pearson Education.

Eisenberger, R., Armeli, S., Rexwinkel, B., Lynch, P.D., \& Rhoades, L. (2001) Reciprocation of perceived organizational support. Journal of Applied Psychology, 86, 42-51. http://dx.doi.org/10.1037/0021-9010.86.1.42, PMid:11302232

Eisenberger, R., Huntington, R., Hutchinson, S., \& Sowa, D. (1986). Perceived organizational support. Journal of Applied Psychology, 71, 500-507.

Ewurum, U.J.F. (2006). Going the extra mile in the workplace to achieve peak performance: A focus on the university system. In I.E. Nwosu \& O.C. Eneh (Eds), Managing job ethics and productivity in Nigerian universities (pp. 105-135). Managing job ethics and productivity
Enugu: Institute of Development Studies.

Farh, J.L., Earley, P.C., \& Lin, S. (1997). Impetus for action: A cultural analysis of justice and extra-role behavior in Chinese society. Administrative Science Quarterly, 42, 421-444. http://dx.doi.org/10.2307/2393733

Farh, J.L., Zhong, C.B., \& Organ, D.W. (2004). Organizational citizenship behavior in the People's Republic of China. Organization Science, 15, 241-253. http://dx.doi. org/10.1287/orsc.1030.0051

Frohman, L.A. (1997). Igniting organizational change from below: The power of personal initiative. Organizational Dynamics, 25(3), 39-53. http://dx.doi. org/10.1016/S0090-2616(97)90046-2
George, J.M., Reed, T.F., Ballard, K.A., Colin, J., \& Fielding, J. (1993). Contacts with AIDs patients as a source of work-related distress: Effects of organizational and social support. Academy of Management Journal, 36, 157-171. http://dx.doi. social support. Academy of Managemer
org/10.2307/256516, PMid:10123743

Gouldner, A.W. (1960). The norm of reciprocity: A preliminary statement. American Sociological Review, 25, 161-167. http://dx.doi.org/10.2307/2092623

Grant, A.M. (2008). Does intrinsic motivation fuel the prosocial fire? Motivational synergy in predicting persistence, performance, and productivity. Journal of Applied Psychology, 93(1), 48-58. http://dx.doi.org/10.1037/0021-9010.93.1.48, PMid:18211134

Griffin, M.A., Neal, A., \& Parker, S.K. (2007). A new model of work role performance: Positive behavior in uncertain and interdependent contexts. Academy of Management Journal, 5, 327-347. http://dx.doi.org/10.5465/ AMJ.2007.24634438

Hoffman, B.J., Blair, C.A., Meriac, J.P., \& Woehr, D.J. (2007). Expanding the criterion domain? A quantitative review of the OCB literature. Journal of Applied Psychology, 92, 555-566. http://dx.doi.org/10.1037/0021-9010.92.2.555, PMid:17371100

Hofstede, G. (1984). Culture's consequences. Newbury Park, CA: Sage Publications.

Ivancevich, J.M., Konopaske, R., \& Matteson, M.T. (2005). Organizational behavior \& management. (7th edn.) New York: McGraw-Hill.

Kreitner, R., \& Kinicki, A. (2004). Organizational behavior. (6th edn.) New York: McGraw-Hill.

Kreitner, R., Kinicki, A., \& Buelens, M. (2002). Organizational behavior. New York McGraw-Hill Companies.

Lambert, S.J. (2000). Added benefits: The link between work-life benefits and organizational citizenship behavior. Academy of Management Journal, 43, 801815. http://dx.doi.org/10.2307/1556411

LePine, J.A., \& Van Dyne, L. (1998). Predicting voice behavior in work groups. Journal of Applied Psychology, 83, 853-868. http://dx.doi.org/10.1037/0021-9010.83.6.853

Li, N., Liang, J., \& Crant, J.M. (2010). The role of personality in job satisfaction and organizational citizenship behavior: A relational perspective. Journa of Applied Psychology, 95, 395-404. http://dx.doi.org/10.1037/a0018079, PMid:20230079

Lindsley, D.H., Brass, D.J., \& Thomas, J.B. (1995). Efficacy-performance spirals: A multilevel perspective. Academy of Management Review, 20, 645-678. http:// dx.doi.org/10.5465/AMR.1995.9508080333, http://dx.doi.org/10.2307/258790

Locke, E.A., \& Latham, G.P. (1990). A theory of goal Setting and task performance. Englewood Cliffs, N.J.: Prentice Hall.

Luszczynska, A., Gutièrrez-Dona, B. \& Schwarzer, R. (2005). General self-efficacy in various domains of human functioning: Evidence from five countries. International Journal of Psychology, 40, 80-89. http://dx.doi.org/10.1080/00207590444000041

Mathieu, J.E., \& Zajac, D.M. (1990). A review and meta-analysis of the antecedents, correlates, and consequences of organizational commitment. Psychological Bulletin, 108, 171-194. http://dx.doi.org/10.1037/0033-2909.108.2.171

McAllister, D.J., Kamdar, D., Morrison, E.W., \& Turban, D.B. (2007). Disentangling role perceptions: How perceived role breath, discretion, instrumentality, and efficacy relate to helping and taking charge. Journal of Applied Psychology, 92(5), 12001211. http://dx.doi.org/10.1037/0021-9010.92.5.1200, PMid:17845080

Meyer, J.P., \& Allen, N.J. (1997). Commitment in the workplace: Theory, research and application. Thousand Oaks, CA: Sage.

Mitchell, T.R., \& Daniels, D. (2003). Motivation. In W.G. Borman \& D.R. Ilgen, R.J. Klimoski, \& I.B. Weiner (Eds), Handbook of psychology, Volume 12: Industrial and organizational psychology (pp. 225-254). New York: John Wiley.

Moon, H., Kamdar, D., Mayer, D.M., \& Takeuchi, R. (2008). Me or we? The role of personality and justice as other-centred antecedents to innovative citizenship behaviors within organizations. Journal of Applied Psychology, 93, 84-94. http:// dx.doi.org/10.1037/0021-9010.93.1.84, PMid:18211137

Moon, H., Van Dyne, L., \& Wrobel, K. (2005). The circumplex model and the future of organizational citizenship research. In D. Turpinseed (Ed), A Handbook on organizational citizenship behavior: A review of 'Good Soldier' activity in organizations (pp. 1-31). New York: Nova Science.

Moorman, R.H. (1991). The relationship between organizational justice and organizational citizenship behaviors: Do fairness perceptions influence employee citizenship? Journal of Applied Psychology, 76, 845-855. http://dx.doi. org/10.1037/0021-9010.76.6.845

Morrison, E.W., \& Phelps, C.C. (1999). Taking charge at work: Extra-role efforts to initiate workplace change. Academy of Management Journal, 42, 403-419. http://dx.doi.org/10.2307/257011

Mowday, R.T., Porter, L.M., \& Steers, R.M. (1982). Employee-organizational linkage. New York: Academic

Munene, J.C. (1995). Not on seat: An investigation of correlates of organizational citizenship in Nigeria. Applied Psychology: An International Review, 44(2), 111122. http://dx.doi.org/10.1111/j.1464-0597.1995.tb01069.x

Ohly, S., \& Fritz, C. (2007). Challenging the status quo: What motivates proactive behavior? Journal of Occupational and Organizational Psychology, 80, 623-629. $\mathrm{http}: / / \mathrm{dx}$.doi.org/10.1348/096317907X180360

Onyishi, I.E. (2006). Relationship between perceived organizational support and organizational citizenship behaviour in a Nigerian sample. Nigerian Journal of Psychological Research, 5, 37-52.

Onyishi, I.E. (2007, November). Psychological empowerment as a factor in taking charge at work. A paper presented at the annual national conference of the Nigerian Psychological Association at Nsukka, Nigeria. 
Organ, D.W. (1988). Organizational citizenship behavior - The good soldier syndrome. Lexington: Lexington Books

Organ, D.W. (1990). The motivational basis of organizational citizenship behavior. In L.L. Cummings \& B.M. Staw (Eds), Research in organizational behavior, Vol. 12 (pp. 43-47). Greenwich, CT: JAL.

Organ, D.W., \& Konovsky, M.A. (1989). Cognitive versus determinants of organizational citizenship behavior. Journal of Applied Psychology, 74, 157-169. http://dx.doi. org/10.1037/0021-9010.74.1.157

Organ, D.W., \& Ryan, K. (1995). A meta-analytic review of attitudinal and dispositional predictors of organizational citizenship behavior. Personnel Psychology, 48, 775 801. http://dx.doi.org/10.1111/j.1744-6570.1995.tb01781.x

Parker, S.K., \& Collins, C.G. (2010). Taking stock: Integrating and differentiating multiple proactive behaviors. Journal of Management, 36, 633-662. http:// dx.doi.org/10.1177/0149206308321554

Parker, S.K, Williams, H., \& Turner, N. (2006). Modeling the antecedents of proactive behavior at ork. Journal of Applied Psychology, 91, 636-652.

Podsakoff, N.P., Whiting, S.W., Podsakoff, P.M., \& Blume, B.D. (2009). Individualand organizational-level consequences of organizational citizenship behavior: A meta-analysis. Journal of Applied Psychology, 94(1), 122-141. http://dx.doi. org/10.1037/a0013079, PMid:19186900

Randall, M.L., Cropanzano, R., Bormann, C.A., \& Birjulin, A. (1999). Organizationa politics and organizational support as predictors of work attitudes, job performance, and organizational citizenship behavior. Journal of Organizational Behavior, 20, 159-174.

Rank, J. Carsten, J.M., Unger, J.M., \& Spector, P.E. (2007). Proactive customer service performance: Relationships with individual, task, and leadership variables. Human Performance, 20, 363-390.

Rousseau, D.M. (1989). Psychological and implied contracts in organizations. Employee Responsibilities and Rights Journals, 2, 121-139. http://dx.doi.org/10.1007/ BF01384942

Scott, S.G., \& Bruce, R.A. (1994). Determinants of innovative behavior: A path mode of innovation in workplace. Academy of Management Journal, 37, 580-607. http://dx.doi.org/10.2307/256701

Settoon, R.P., Bennett, N., \& Liden, R.C. (1996). Social exchange in organizations: Perceived organizational support, leader-member exchange, and employee Perceived organizational support, leader-member exchange, and employee
reciprocity. Journal of Applied Psychology, 81, 219-227. http://dx.doi. reciprocity. Journal of Applied

Shaughnessy, J.J., Zechmeister, E.B., \& Zechmeister, J.S. (2000). Research methods in psychology. (5th edn). Boston: McGraw-Hill.

Shea, C.M. \& Howell, J.M. (2000). Efficacy-performance spirals: An empirical test. Journa of Management, 26, 791-812. http://dx.doi.org/10.1016/S0149-2063(00)00056-8, http://dx.doi.org/10.1177/014920630002600409
Sherer, M., Maddux, J.E., Mercandante, B., Prentice-Dunn, S., Jacobs, B., \& Rogers, R.W. (1982). The self-efficacy scale: Construction and validation. Psychological Reports, 51, 663-671. http://dx.doi.org/10.2466/pr0.1982.51.2.663

Sitkin, S.B., \& Pablo, A.L. (1992). Reconceptualizing the determinants of risk behavior Academy of Management Review, 17, 19-38. http://dx.doi.org/10.5465/ AMR.1992.4279564, http://dx.doi.org/10.2307/258646

Smith, C.A., Organ, D.W., \& Near, J.P. (1983). Organizational citizenship Behavior: Its nature and antecedents. Journal of Applied Psychology, 68, 653-663. http:// dx.doi.org/10.1037/0021-9010.68.4.653

Speier, C., \& Frese, M. (1997). Generalized self-efficacy as a mediator and moderator between control and complexity at work and personal initiative: A longitudinal field study in East Germany. Human Performance, 10, 171-192. http://dx.doi. org/10.1207/s15327043hup1002 7

Stajkovic, A.D., \& Luthans, F. (1998). Self-efficacy and work-related performance: A meta-analysis. Psychological Bulletin, 124, 240-261. http://dx.doi. org/10.1037/0033-2909.124.2.240

Staw, B.M., \& Boettger, R.D. (1990). Task revision: A neglected form of work performance. Academy of Management Journal, 33, 534-559. http://dx.doi. org $/ 10.2307 / 256580$

Steers, R.M. (1977). Antecedents and outcomes of organizational commitment. Administrative Science Quarterly, 22, 46-56. http://dx.doi.org/10.2307/2391745, PMid:10236068

Suresh, S., \& Venkatammal, P. (2010). Antecedents of organizational citizenship behaviour. Journal of the Indian Academy of Applied Psychology, 36, 276-286.

Van Dyne, L., Cummings, L.L., \& Parks, J.M. (1995). Extra role behaviors: In pursuit of construct and definitional clarity. In L.L. Cummings, \& B.M. Staw (Eds), Research in organizational behavior, Vol. 17 (pp. 215-285). Greenwich, CT: JAI Press.

Van Maanen, J., \& Schein, E.H. (1979). Toward a theory of organizational socialization. In B.M. Staw (Ed), Research in Organizational Behavior (pp. 209-264). Greenwich, CT: JAl Press.

Vroom, V.H. (1964). Work and motivation. New York: Wiley

Wayne, S.J., Shore, L.M., \& Liden, R.C. (1997). Perceived organizational support and leader - member exchange: A social exchange perspective. Academy of Management Journal, 40, 82-111. http://dx.doi.org/10.2307/257021

Withey, M.J., \& Cooper, W.H. (1989). Predicting exit, voice, loyalty, and neglect. Administrative Science Quarterly, 34, 521-539. http://dx.doi. org/10.2307/2393565

Yoon, J., \& Thye, S. (2000). Supervisors support in the workplace: Legitimacy and positive affectivity. Journal of Social Psychology, 140, 295-316. http://dx.doi. org/10.1080/00224540009600472, PMid:10902372 